\title{
FAIRNESS AND SOCIAL JUSTICE IN LANGUAGE ASSESSMENT
}

Abstract: This chapter offers a critical historical overview of the research into and conceptions of fairness and justice in the language assessment literature. The focus is primarily on high-stakes assessment practices, since this is the area in which most of the relevant research is conducted. In order to clarify the meaning and origin of the current conceptions of fairness and justice, this chapter opens by going back to the original works in moral and political philosophy. Afterwards, fairness, justice, and their relationship to validity are discussed.

Key words: fairness, justice, social justice, validity high-stakes language testing, language assessment

\author{
Dr. Bart Deygers \\ FWO Vlaanderen and Centrum voor Taal \& Onderwijs \\ KU Leuven \\ Blijde Inkomststraat 7 \\ 3000 Leuven \\ Belgium \\ bart.deygers@kuleuven.be
}

\section{INTRODUCTION}

In 1963, the United States District Court ruled that the test used by the State of Louisiana to determine whether low-educated citizens (The State of Louisiana 1963a, b) could register to vote was unconstitutional "because of its unlawful purpose, operation, and inescapably discriminatory effect" (United States v. State of Louisiana 225F. Supp. 353, 1963, p. 398). This test included a language and literacy section of questionable validity that was scored at the whim of the registrar and had the purpose to reduce the number of African American voters. A somewhat similar but more welldocumented case in the language testing literature is that of the dictation test, which was part of the explicitly discriminatory White Australia policy (McNamara and Roever 2006; McNamara 2009, 2012). Until it was abolished in 1958, this test served to exclude newly arrived but unwanted immigrants by giving them a dictation in a language they were not familiar with. Historical examples such as these are arresting reminders of how language assessment can reinforce or mitigate systemic social inequalities (Spolsky 2013). Studying such inequalities as they stem from social structures, is the focus of social justice (Adams 2014).

This chapter aims to disentangle and clarify the concepts of fairness and social justice with regards to language assessment by taking a double approach. In the first part of the chapter, the moral and political philosophy on social justice will be introduced. This is important, because the language assessment literature has not always engaged in a careful interpretation of these principles. So, in order to clarify the meaning and relative position of fairness and justice, this chapter will first go back to foundational works by Kant, Rawls, Sen, Nussbaum, and Young. The second part will offer a historical and conceptual overview of how fairness and justice have been considered in language assessment, from the early beginnings until today. Finally, 
after addressing the relationship between fairness, justice and validity, the conclusion of the chapter contains a brief discussion of guidelines regarding fair and just language assessment.

\section{FAIRNESS AND SOCIAL JUSTICE IN POLITICAL AND MORAL PHILOSOPHY}

The purpose of this section is to introduce the political and moral philosophy on which language assessment principles are built. This will help to disentangle confounded concepts that are commonly confounded, and to clarify definitions that may have become blurred over time.

\section{Ethics, morality, and nomenclature}

Broadly speaking, the study of ethics is concerned with answering the question of how to live good lives, while morality focuses on how to treat others. Political morality zooms in on how systems should treat individuals (Young 2011; Dworkin 2013). Not all language testing authors adhere to this distinction between ethics and morality, however. In the language assessment literature, ethics are usually seen as the agreed-upon social practices and collective responsibilities of assessment professionals. Morality, on the other hand, is seen as pertaining to the conscience of the individual testing professional (e.g., Davies 2012). In order to preserve consistency with the language assessment literature, this chapter will use the term "code of ethics" in the way that is commonly accepted in the field: "sets of principles that draw on moral philosophy and are intended to guide good professional conduct" (Boyd and Davies 2002, p. 304). The term morality will be used to refer to the relationship among individuals and between individuals and societal structures. Additionally, in this chapter, "justice" will be used synonymously with social justice, as is customary in language assessment literature (e.g., McNamara and Ryan 2011). When another type of justice is referred to, it will be explicitly mentioned (e.g., criminal justice, distributive justice).

\section{Justice, from Aristotle to Mill}

In philosophy, justice has been an object of study since Aristotle's Nicomachean Ethics (350BC). Aristotle distinguished between legal and distributive justice - the former referring to a citizen's duty to respect the law and the latter to the duty to treat others fairly. Distributive justice is a discipline within moral philosophy that is concerned with deciding on how goods should be distributed in society. The purpose of distributive justice is strikingly similar to the goal of high-stakes tests, as defined by Cronbach: "[testing] has always been intended as an impartial way to perform a political function - that of determining who gets what" (Cronbach 1984, p. 5). Cronbach does not refer to the distribution of material goods, but of opportunities, services and societal statuses. Whereas distributive justice refers to the fair reallocation of material goods and social justice to the distribution of opportunities, both are manifestations of the distributive paradigm, and in practice the two terms are often conflated (Young 1990).

In Western philosophy, three schools have taken different approaches to the ethical puzzle of deciding who is entitled to which material or other benefits in 
society. Utilitarianism would solve the matter by taking the course of action that causes the greatest happiness for the greatest number of people (Mill 1861 / 2015). Libertarianism would focus on allowing for maximal individual liberty and minimal government interference (Nozick 1974), and the human rights approach, would consider certain individual rights so fundamental that there could be no justifiable utilitarian or libertarian grounds for violating them (Sandel 2010). The source of the human rights approach can be found in Immanuel Kant's (1785 / 2016) Fundamental Principles of the Metaphysic of Morals. As will be shown below, the human rights approach has had a far more substantial influence on fairness and justice in language assessment than utilitarianism and libertarianism (Deygers 2017).

\section{Kant's categorical approach to morality}

Kant accepted the utilitarian idea that human nature is to seek pleasure and avoid pain, but rejected the notion that reason is controlled by a desire to maximize happiness and minimize pain (Hume 1738 / 1978). Freedom, Kant stated, is in the human ability to suppress pleasure-seeking impulses and to pursue a goal that has intrinsic moral worth. Human dignity stems precisely from this ability to make choices autonomously and consciously. The idea of autonomously choosing to do what is morally right, because it is morally right, is at the core of Kant's conception of morality (Sandel 2010). For Kant, an action has moral worth only if it is done for the right reasons. In order to decide when a reason is right, he submitted three formulations of the categorical imperative - a moral law that must be obeyed under all circumstances.

The first formulation prevents people from favoring their own desires over the best interests of others: "Act only according to that maxim whereby you can at the same time will that it should become a universal law" (Kant 1785 / 2016, p. 421). The second formulation tightens and limits the first by stating that no moral law could be acceptable if it denied the freedom and dignity of others: "Act in such a way that you treat humanity, whether in your own person or in the person of any other, never merely as a means to an end, but always at the same time as an end" (Kant 1785 / 2016, p. 429). The core idea of the third formulation is that people must only act on those principles that could gain acceptance by a universal community of rational and autonomous people: "Act in accordance with the maxims of a member giving universal laws for a merely possible kingdom of ends" (Kant 1785 / 2016, p. 439).

Although the enduring influence of Kant on moral and political philosophy is undeniable (Sandel 2010), many modern philosophers may be Kantian, without adhering to a close interpretation of Kant's duty-based ethics and morality. What makes them Kantian, is the foundational respect for human dignity and human reason (for a thorough examination of Kant's ethics versus Kantian ethics, see Wood 2008). The first article of the Universal Declaration of Human Rights, for example, carries an undeniable Kantian signature, but does not highlight Kant's duty-based severity: "All human beings are born free and equal in dignity and rights. They are endowed with reason and conscience and should act towards one another in a spirit of brotherhood" (UN General Assembly 1948).

In language assessment, Kantian ethics imply that testing practices which humiliate, degrade, or dehumanize candidates, solely use them for financial gain, or do not recognize their individual identity (Young 1990; Kaufmann et al. 2010) are morally reprehensible, even if the outcomes of the test are psychometrically 
defensible. When using Kantian ideas as guidelines for morally acceptable testing practices, it is clear there can never be any justification for not respecting test takers' background, for subjecting them to humiliating examination conditions, or for taking advantage of test takers' less powerful position (e.g., when applying for citizenship, or education) for financial gain, without considering their rights as individuals. These ideas are clearly visible in the Code of Ethics of the International Language Testing Association (ILTA 2000).

In philosophy, Kantian ideas have had a profound influence on John Rawls, arguably the most important twentieth century philosopher in the distributive justice paradigm.

\section{Rawls' justice as fairness}

One of the first modern philosophers to read Kant not "as a morality of austere command but [as] an ethic of mutual respect and self-esteem" (Rawls 1971, p. 225), John Rawls' writings focused on how societal institutions should provide the just distribution of goods, services, and opportunities. Rawls' theory was written to counterbalance utilitarian tendencies (i.e., catering to the needs of the greatest number of people) in society. For Rawls, utilitarianism entails the risk of endangering the fundamental rights of underprivileged individuals. Safeguarding those rights by promoting fairness as a guiding principle for justice, is at the heart of Rawlsian philosophy. Now, sixty years after Rawls' first major publication (Rawls 1958), it is impossible for authors of a book or paper on social or distributive justice to forego his ideas. In the language assessment literature, no ideas on justice have had more impact than Rawls' (e.g., Cronbach 1976; Kunnan 2000, 2018; Davies 2010; McNamara and Ryan 2011)

The basic question put forward by Rawls is: What kind of society would we choose if we did not know our own place in the world? In order to come to an answer, Rawls introduces the metaphor of the veil of ignorance. If people had to decide on the basic structure of society from behind this veil - which hid information about their position in society, about their wealth, health, ethnicity, or gender - they would choose fairness as the basic guiding principle (Rawls 1958, 1971, 2001). Consequently, people would choose a society that is fair, and offers equal opportunities to all.

From this, Rawls deduced two main principles of justice, which have influenced the idea of the welfare state to this day (Reisch 2014). Because there is hierarchy to these principles, the second cannot be addressed before the first is satisfied. The first principle guarantees that all citizens enjoy maximal equality in society. Thus, no societal arrangement can ever be just if it lacks a system of equal basic liberties.

"Each person has the same indefeasible claim to a fully adequate scheme of equal basic liberties, which scheme is compatible with the same scheme of liberties for all"

(Rawls 2001, p. 42).

Rawls' second principle accepts that social and economic inequalities will arise, but even in this context it is important that all members of society have equal access to the same positions in life (2a). Moreover, the difference principle (2b) states 
that if inequalities do arise, they should be the most beneficial to the least-endowed citizens.

"Social and economic inequalities are to satisfy two conditions:

a. They are to be attached to offices and positions open to all under conditions of fair equality of opportunity;

b. They are to be to the greatest benefit of the least-advantaged members of society

(Rawls 2001, p. 42 - 43)

To be clear, Rawls defines fairness as the absence of bias. Since fairness objectiveness - is the precondition for justice (Rawls 2001), no ruling could be just if it is based on a biased system in which certain groups of people systematically receive more opportunities. Instead, Rawls argues for a system where everybody has equal opportunities, and where redistributive measures bring the most benefits to those who need them the most.

\section{After Rawls: the capability approach}

Offering a full overview of Rawls' impact on philosophy and policy exceeds the scope of this chapter (but see for example Laborde 2002). Nevertheless, it is important to include the work of Rawlsian thinkers Amartya Sen and Martha Nussbaum in this section since their capability approach has influenced the writings on justice in language assessment (e.g., Kunnan 2014, 2018).

Even though Sen and Nussbaum applaud the Rawlsian approach for the prioritization of fairness, equity and objectivity, they criticize its proponents (e.g., Rawls 2001; Pogge 2010; Dworkin 2013) for focusing too much on equality in terms of primary goods instead of on equality in terms of capabilities (Sen 1980, 1992). Primary goods are items, liberties, or services that every person would want regardless of any other desired they held (e.g., freedom of thought, freedom of movement - see Rawls 2001; Boylan 2004; Dworkin 2013). A capability, on the other hand, refers to "a person's ability to do valuable acts or reach valuable states of being" (Sen 1993, p. 30). As such, the capability approach judges the justness of a society or system by the extent to which it allows people to pursue valued goals (Sen 1993; Nussbaum 2002).

Secondly, Sen noted that Rawls' focus on determining the conditions for perfectly just societal institutions cannot yield a definitive outcome, since there will never be unanimous agreement about what perfect justice entails. Instead, Sen promotes a more pragmatic approach, which focuses on reducing known injustices, rather than on defining what perfect justice entails (Sen 2010).

Thirdly, Sen criticizes Rawls' veil of ignorance as a thought experiment, since it is unrealistic to ask people to imagine a state of ignorance regarding their status in life. Objectivity, Sen argues, can only be reached by involving a wide array of subjective perspectives (Nagel 1989; Sen 2010). Thus, the justness of a system can only be judged when the viewpoints of all stakeholders are considered.

Finally, most post-Rawlsian philosophers agree on the need for just societal institutions to be based on robust evidence (e.g., Phillips 2007; Sen 2010; Dworkin 2013). Reminding of Kant's dictum that an action which leads to a morally desirable outcome only has moral worth if it is done for the right reason, these modern 
philosophers argue that a policy can only be just if it is based on a reasoned use of evidence (Sen 2010).

\section{Political and moral philosophy on education and assessment}

The literature on social justice in education often focuses on schools as reproduction sites of social inequality (e.g., Bourdieu 1991; Ball 2003), or as emancipatory transformation grounds, where systemic inequalities can be reversed (Walker and Unterhalter 2007; Van den Branden 2015). Nevertheless, irrespective of the approach taken to the emancipatory potential of education, it is safe to state that all human rights philosophers consider access to education a basic human right at very much the same level as food, shelter, and bodily integrity (Nussbaum 2000; Rawls 2001; Boylan 2004; Walker and Unterhalter 2007; Stein 2016). Consequently, there is broad consensus that a just educational system should be governed by principles of fairness and equal opportunity (Rawls 2001), and that education should allow people to determine and pursue valued goals in life (Nussbaum 2002; Sen 2010). This has implications for assessment that provides access to education, and for the assessment going on during the educational process.

Any kind of testing entails a power imbalance. The person being tested is judged by a person or organization, who has the power to decide over the candidate's fate (Foucault 1977; Shohamy 2001). Since the candidate bears the brunt of the decision, but is usually not allowed to partake in the decision-making process, most tests qualify as systemic coercion (Valentini 2012). Such systems are not necessarily unjust, Rawls and later philosophers argue, but they must be free from bias. Moreover, everybody who wants to partake in a test, should be able to do so. Consequently, tests should not withhold certain groups of people from taking part, unless there is good reason to do so.

Regarding access to education, one of the most prominent voices of the Rawlsian school is Ronald Dworkin. He wrote extensively about a university's right to apply affirmative action for students who come from a less privileged background (e.g., Dworkin 2000). Dworkin's solution to unequal starting positions in education, is to ensure that people from a disadvantaged background are compensated for any inhibiting factors that are outside of their control. Once those factors, stemming largely from chance, are remedied, people are responsible for their own successes and failures later in life (Dworkin 2002, 2003). To an extent Dworkin's ideas are in opposition to the social justice philosophers who focus less on individual responsibility and more on structural inequalities and systemic bias (Young 1990; Bourdieu 1991; Roemer 1996). These authors would point out that affirmative action to determine access to education is too little, too late, since educational justice is not about applying positive discrimination at certain points, but about remedying a systemic inequality of opportunities. In this respect, Young introduced the concept of "thrownness" to denote that people do not choose their own circumstances but are thrown into a social world that will determine their opportunities for them (Young 1990; Rawls 2001).

Even though not all authors would stress structure over agency to this extent (e.g., Sen 2010 considers human agency a vital component), there is consensus that structural educational social injustice is a reality. It occurs when certain groups of people are systematically given fewer opportunities for pursuing valued goals, either because of a biased policy or because of collectively enacted implicit societal norms (Nussbaum 2000; Young 2011). As long as schools play a role in normalizing and 
reinforcing unequal opportunities, they contribute to the cyclical reaffirmation of unequal opportunities (Young 1990, 2011; Adams 2014). Since systemic inequality is the result of interactions between individuals, every individual involved in education is responsible for reducing bias during classes and during assessment (Giddens 1979; Young 2011; Adams 2014). Nevertheless, since systemic forces are enacted largely implicitly and unconsciously (Bourdieu 1984; Young 2011), that is easier said than done.

Summarizing the above, there is consensus that everybody has the right to equal educational opportunities (Nussbaum 2000; Boylan 2004), and to an education that allows them to pursue valuable life goals (Sen 1980, 1993). Everybody also has the right to an education that is free from systemic inequality (Walker and Unterhalter 2007; Adams 2014). In this process, assessment plays a decisive role.

\section{FAIRNESS}

Fairness is a rather intuitive concept that concerns receiving equal treatment or rewards when equality is due (Rescher 2002). This desire for equality appears to be a universal part of human nature, displayed by children from as young as four years old from the most diverse societies (Blake et al. 2015). Given the natural inclination of humans to strive for equity, it is somewhat unsurprising that fairness has been a perennial concern in testing as well as in philosophy.

Language testers may consider fairness either narrowly or broadly. The narrow conceptualization considers fairness as a psychometrical matter, aimed at reducing bias (McNamara and Ryan 2011). The broader definition of fairness also includes the absence of bias, but goes beyond it by considering a range of issues, from equal access to rater severity (McNamara and Roever 2006; Shaw and Imam 2013; AERA 2014). In this section, we will consider both conceptualizations, beginning with the narrow one.

As the focus in the chapter shifts from the philosophical to the psychometrical, it is important to highlight that the term "bias" as used in assessment may differ from the bias identified by Rawlsian thinkers. In both fields, bias denotes an absence of objectivity, but the approaches taken to avoid or counteract this deficiency may differ. Language assessment, being a practice-driven multidisciplinary field, uses a more concrete methodology than the propositions put forward by the above-mentioned philosophers. Nevertheless, even though Rawls' writing about bias may not be specific enough to allow for concrete operationalization, he did see merit in compensating for biased judgments about primary goods, and saw bias as a threat to validity.

"It is unreasonable to demand great precision, yet these estimates [i.e., individual judgments about the distribution of primary goods] cannot be left to our unguided intuition. Moreover, they may be based on ethical and other notions, not to mention bias and self-interest, which puts their validity in question."

(Rawls 1971, p. 78)

As this quote shows, Rawls deemed the demand for great precision in mitigating biased judgments to be unreasonable. In assessment and psychometrics, however, achieving great statistical precision has been a perennial quest. 


\section{Fairness and bias}

\section{The roots of bias research}

Quite likely, a desire for impartiality is what inspired the creation of the Chinese Imperial test - perhaps the oldest and longest-running public selection examination, which was used from 605 until 1905 to select bureaucratic staff in the service of the emperor of China (Spolsky 1997; Stein 2016). Later, in the postrevolutionary Europe of the enlightenment, tests were used to pursue the meritocratic ideal of selecting the most qualified candidates (Spolsky 1997; Reisch 2014; Stein 2016). During this era, educational institutions in the Anglo-American tradition were among the first to use tests as selection mechanisms in the modern sense (Stein 2016). Rather quickly, scholars discovered that these tests were not only measuring construct-relevant variance, but that other factors appeared to determine the score as well.

Latham's (1877) observation that raters differed in severity laid the groundwork for Edgeworth (1888) to investigate the backgrounds of candidates, and discover that wealthier candidates were more likely to do well in examinations. In a related study, Dexter (1903) showed that students who did well academically, were twice as likely to become part of the American high society. Drawing on Dexter, Cattell (1905) later called for the standardization of university examinations, in order to ensure that candidates were judged on merit, not on social standing. Today, the trends uncovered by Edgeworth and his colleagues would be referred to as bias: systematic construct-irrelevant variance that unfairly disadvantages specific populations (McNamara and Roever 2006).

An important condition for bias is the presence of differential item functioning (DIF), which occurs when certain test items persistently and significantly function differentially for different populations after controlling for the test takers' ability level (Aryadoust et al. 2011). A psychometric concept, DIF is not necessarily problematic in itself, since certain groups could systematically underperform for constructrelevant reasons (Linn and Drasgow 1987).

"Differential item functioning is a necessary but not sufficient condition for bias because a test item that functions differently for two groups might do so because it advantages one group in a construct-irrelevant way, but there might also be legitimate reasons for differential functioning."

(McNamara \& Roever 2006, p. 83)

Bias occurs, however, when large numbers of items systematically and demonstrably (dis)advantage specific populations on construct-irrelevant grounds, such as gender, educational background, or home language (Elder 1997; Kane 2010; Xi 2010a; Shaw and Imam 2013).

Early research into the differential performances of different subgroups on the same tests discovered that not all groups performed equally well on all tests. Links between performance and socio-economic (Stern 1914; Binet and Simon 1916) or ethnic background (Weintrob and Weintrob 1912) were found, but not all researchers necessarily interpreted this as a moral or ethical problem. Dexter (1903), for example, saw the connection between high test scores and high socio-economic status as a sign that tests selected the right people, rather than as a sign of potential bias. 
During the second half of the twentieth century, the term fairness came into use. Cleary (1968), examining racial bias in tests, proposed an operationalization of fairness that approaches today's conception of DIF. For Cleary, a test was fair if there were no systematic performance differences in different groups of test takers. Three years later, Thorndike (1971) pointed out that a systematic performance difference does not necessarily imply unfairness. A test is only unfair when two groups of equally able test takers gain markedly different scores. In order to establish whether that is the case, Thorndike stated, it would be necessary to determine the base rate performances of different populations so as to allow for partialing out the ability level of different groups of test takers. In the same year as Thorndike's influential paper, a third paradigm entered the debate, highlighting political and ethical concerns (Oliveri et al. 2013). Darlington (1971) introduced the broad definition of fairness by focusing on how value systems may lead to bias. This idea was is embraced by Flaugher (1974) who advocated for cultural awareness in test development.

By the mid-1970s, at least five models of fairness had been proposed, but none truly managed to achieve the ideal of "culture-fairness" (Cronbach 1976; Petersen and Novick 1976). In the same year, Rawls was referenced for perhaps the first time in the assessment literature, when Cronbach includes the difference principle in a paper on fairness (Cronbach 1976).

\section{Bias in language testing: enter Rasch}

In language assessment research, there is a time before and after the introduction of the Rasch model. Before, studies often examined the effect of background knowledge (e.g., Alderson and Urquhart 1985; Hale 1988), native language (L1) (e.g., Swinton and Powers 1980), cultural background (e.g., Chen and Henning 1985) or ethnicity (e.g., Zeidner 1987) on test performance by relying on item difficulty alone, without considering test-taker ability. The basic Rasch model, however, considers both test-taker ability and item difficulty. The premise of the model is that the probability of a test taker getting a dichotomously scored item right depends on the difference between candidate ability and item difficulty. These two parameters are estimated separately, but are mapped onto a common scale (Barkaoui 2014).

McNamara and Knoch's (2012) historical overview of the impact of the Rasch models on language testing shows how a rather small group of researchers from the US, the UK, Australia and the Netherlands examined the potential of the basic Rasch model for test validation (e.g., De Jong 1983). It was only after the introduction of many-facets Rasch measurement (MFRM, Linacre 1989) and the FACETS program (Linacre 1989), however, that the method truly gained momentum.

Building on the basic Rasch model, MFRM allows researchers to examine polytomous and ordinal items, and to define parameters other than test taker ability and item difficulty, such as rater severity or certain demographic variables. As such, MFRM offered an answer to the rating problems observed a century earlier (Latham 1877), and to the problems of quantifying and resolving socio-economic or racial bias (Cleary 1968; Darlington 1971; Petersen and Novick 1976). For the past thirty years, the MFRM has been growing into a leading method used to investigate bias and 
fairness (McNamara and Knoch 2012), although other statistical avenues are being explored successfully (Xi 2010b; Li and Suen 2013).

\section{A broader conception of fairness}

Up until now, the discussion of fairness in this chapter has focused on the narrow conception (i.e., limited to psychometrically traceable item bias). This section discusses a broader conception of fairness, as including sensitivity reviews, considerations of equal access and equitable treatment, and rater severity (McNamara and Roever 2006).

Sensitivity reviews typically take place before and during test construction. Taboo lists can be used to preemptively rule out certain topics as test material, since they may adversely affect the performance of certain test takers, (e.g., religion, sexuality, politics). During test construction, an international and culturally diverse review board can scrutinize test items for potential insensitivities or bias. When this is done extensively, and when all stakeholders are included in this process, such a review may begin to address the objectivity approach advocated by Sen (2010), and the right to objective assessment argued by Stein (2016).

Regarding equal access, it is clear that if language assessment opens the way to educational opportunities or to non-trivial statuses, goods and services (e.g., citizenship, social housing, and employment), the level of effort involved in partaking in the test should be comparable for all people involved. For example: If, as is increasingly the case, European nations demand non-EU nationals to pass a language test before they are admitted to the host country (Van Avermaet and Pulinx 2013), fairness demands that gaining access to the test site is feasible for all (Rawls 2001). Similarly, all test takers should receive equal treatment during the test, regardless of any demographic or physical differences (Nussbaum 2002). The test design should not exclude people from partaking, or negatively impact test takers' performances. If it does, accommodations should be available to compensate for any unequal opportunities that may arise (ILTA 2007). Often, these will include screen readers for the visually impaired, compensatory measures for candidates with dyslexia, and the like (Abedi 2014). To date, comparatively little research has examined the fair assessment of low-educated, low-literate learners, who make up for a substantial proportion of the citizenship testing population (Carlsen 2017).

Additionally and importantly, the rating procedure can unduly influence a candidate's score. Rater severity was the topic of one of the first fairness studies (Latham 1877), and the study of rater behavior, rater consistency, and rater severity has been a longtime focus of language assessment research and good practice guidelines (EALTA 2000; ILTA 2007). In an influential early study Diederich and colleagues (1961) found that different raters may use almost entire score range when judging the same performances without scoring criteria. Intuition is generally not a recommended approach to achieve rating reliability, but rating scales too do not always provide guarantees for reliable scoring, even after rater training (Elder et al. 2005). Rater reliability is not fixed, but results from the interaction between the type of rating scale, the quality of the criteria, the experience of the rater, and individual differences in severity (Weigle 2002; Barkaoui 2010; Galaczi et al. 2011; Fulcher et al. 2011; Isaacs and Thomson 2013). As long as raters are consistently deviant, however, MFRM analyses can be used to compensate for severity or leniency issues. Since the 1990s, dozens of studies have been published about this well-established topic (McNamara and Knoch 2012). Nevertheless, even when the rating reliability 
indices are high, and even when MFRM analyses are applied methodically and rigorously, there are no guarantees that the raters will interpret the same criteria similarly. In fact, empirical studies suggest, that the interpretation of a rating scale is fundamentally impacted by rater experience, task types, surface elements, and rater intuition (Lumley 2002; Barkaoui 2010; Fulcher et al. 2011; Isaacs and Thomson 2013), which in turn, raises important issues regarding scoring validity (Harsch and Martin 2013; Deygers and Van Gorp 2015).

The relationship between fairness, justice and validity will be discussed below. For now, we can conclude that fairness research, in its narrow and broad conceptualization, has been a vital part of the history of language assessment, and has been at the heart of some important technological and statistical innovations in the field. However, in spite of these important methodological innovations, and in spite of the progress made during some 150 years of research, there is no universally accepted method of eliminating bias. Quite clearly, and contrary to what earlier fairness researchers assumed (Binet and Simon 1916), fairness has proven to be an issue that cannot be easily resolved. There is no readymade formula for fair testing (McNamara and Roever 2006). At best, it seems, unfairness can be contained, but not eradicated.

\section{JUSTICE IN LANGUAGE ASSESSMENT}

The section above indicates that the operationalization of fairness in the assessment literature aligns rather well with the Rawlsian notion of avoiding bias and ensuring equal access. Moreover, fairness has been a matter of educational research for a century, but the interest in justice is more recent (Davies 1977; Spolsky 1981, 1995). As a telling case in point, Web of Science returns no results for the query "social justice AND assessment" between 1980 and 1990. For the following two decades, respectively 17 and 106 papers are listed, compared to 213 for the seven years after 2010. The growing number of papers on justice aligns with an increased interest in test ethics, and with a growing use of language tests for high-stakes purposes such as citizenship (McNamara and Shohamy 2008; Van Avermaet and Pulinx 2013).

A number of important publications have kindled the interest in the role of language tests in society. Messick's (1989) chapter on validity brought the concept of impact front and center, and important subsequent publications have expanded on that basis. Even though many valuable ideas have been expressed in these publications, however, their approaches to fairness and justice have not always been mutually compatible, and have not always agreed with accepted principles in moral and political philosophy.

First, it is important to introduce the ILTA (2000) Code of Ethics, perhaps the most essential document regarding justice in the field of language assessment. The Code of Ethics contains nine amended principles, ranging from respecting test takers' dignity (Principle 1) to considering unintended effects of tests (Principle 9). Its purpose is to promote beneficence, non-maleficence, justice, and respect for autonomy and for civil society as central to the practice of language assessment (ILTA 2000, p. 1).

These principles explicitly and visibly draw on moral philosophy, and bear a clear Kantian signature in its foregrounding of human dignity. Principle one states: 
"Language testers shall have respect for the humanity and dignity of each of their test takers. They shall provide them with the best possible professional consideration and shall respect all persons' needs, values and cultures in the provision of their language testing service" (ILTA 2000, p. 1). The annotation to the third principle reads: "The human rights of the research subject shall always take precedence over the interests of science or society" (ILTA 2000, p. 3). As will become clear in the following section, ILTA's code has had a noticeable influence on the conceptions of justice that have been put forward in the literature.

\section{Untangling fairness and justice}

Messick's groundbreaking chapter (1989) on validity stressed the importance of the social consequences of tests and distinguished between an evidential and a consequential basis for validity. The evidential basis concerns construct validity, and the avoidance of construct underrepresentation and construct irrelevant variance. The consequential basis refers to the values that shape a testing policy and to the social consequences of tests. In line with Rawls, Messick links fairness to the evidential basis of validity, and the importance it assigns to avoiding bias on construct-irrelevant grounds. Messick also uses the term justice, but in a somewhat ambivalent way. Messick's justice has two components: the position of a test in a larger societal policy, but also the consequences that are attached to test scores.

In an important paper on justice and fairness in citizenship testing, McNamara and Ryan (2011) revisit Messick's chapter to clarify the use of terminology. Staying true to both Messick and to Rawls, they define fairness as "the extent to which the test quality, especially its psychometric quality, ensures procedural equality for individual and subgroups of test-takers and the adequacy of the representation of the construct in test materials and procedures" (McNamara \& Ryan 2011, p. 163). They continue to make an important distinction between fairness and justice: fairness is test-internal, justice is test-external. In other words, investigating fairness implies presupposing the existence of a test for a certain purpose. To investigating justice, however, researchers take a step back, consider how a test functions in the larger whole of society, and which functions the test scores perform. Justice requires that researchers think critically about the why a test is used in the first place "not only in terms of its effects and consequences but in terms of the social values it embodies" (McNamara \& Ryan 2011, p. 165).

Thus, McNamara and Ryan link fairness to the evidential basis of validity, and justice to its consequential basis. In an important deviation from the Rawlsian approach, however, they do not give fairness priority over justice. In their framework, a test can be just even if it is unfair. The example they give is that of a university admission test: In practice, these tests may be unfairly biased, even though there is general support for the idea that prospective students need to demonstrate a certain proficiency level in the language of instruction before they can gain admission to university. For Rawls, however, the mere justifiability of an idea, could never qualify the practice as just. Put differently, if a justifiable idea is put into practice in a way that does not guarantee equality of opportunity and freedom from bias for everybody involved, it can never be just (Rawls 2001; Sen 2010; Sandel 2010; Stein 2016).

Even though McNamara and Ryan did not maintain Rawls' prioritization of fairness over justice, they did stay close to his conception of fairness. Other authors have deviated more from the original philosophical concepts. Kane (2010), for 
example, does not define justice altogether, but differentiates between substantive fairness - the absence of bias - and procedural fairness - the use of a test score. There are two conceptual problems with this proposition. First, it appears to consider fairness a proxy for justice, rather than a precondition, and second, it focuses on the individual test taker alone, whereas justice demands a focus on the larger society (Sen, 2010).

Throughout his career, Alan Davies remained skeptical towards fairness and justice. In his introduction to the 1997 special issue of Language Testing devoted to test ethics, Davies considered the focus of justice to be on the role of tests in society, and the focus of fairness to be on the individual test-taker. In later publications, however, Davies dismissed attempts to delineate justice and fairness as futile (Davies 2010), or suggested equating justice with legality (e.g., Davies 2012). Other authors, too have proposed diverging ideas on fairness and justice. Some have used fairness and justice synonymously (e.g., Shaw and Imam 2013), have avoided a clear distinction by defining fairness as "something that may, but not necessarily, be synonymous with justice” (Walters 2012, p. 470),

In contrast, Anthony Kunnan, one of the first language assessment researchers to demand attention for fairness and justice, has always sought to offer clear operationalizations of fairness and justice. Kunnan (2000) can also be credited with highlighting the important idea that the presence of a test may introduce a societal inequity or imbalance that would not have occurred in the absence of that test.

In his first contributions, Kunnan (2000) considered justice as part of fairness, whereby fairness was considered an overarching concept that included validity and justice. In his definition of justice, Kunnan referred to matters of litigation, which is substantially different from distributive and social justice. Kunnan's subsequently published Test Fairness Framework (Kunnan 2004, 2010) maintained fairness as a superordinate concept, consisting of both justice and beneficence. Somewhat confusingly, this framework described justice as freedom from bias, and beneficence as the impact of a test on a wider society. In recent work, Kunnan $(2014,2018)$ no longer defines justice as a component of fairness, but considers them as two distinct principles. In a Rawlsian turn, he prioritizes fairness over justice (i.e., a test can never be just if it is not fair). Kunnan's most recent publication (2018), introduces a principle of fairness and a principle of justice, which link with Stein's (2016) principles (see below). The principle of fairness states that: "An assessment ought to be fair to all test takers; that is, there is a presumption of treating every test taker with equal respect". The four sub principles show that Kunnan is using a broad definition of fairness, since they include to the right to acquire the necessary skills, knowledge or abilities to pass the test, the right to meaningful, unbiased, and construct-relevant assessment, and the right to equal access and equitable treatment. The principle of justice is less concrete. In reference to Rawls, he considers justice to be an institutional matter: "an assessment institution ought to be just, bring about benefits in society, promote positive values, and advance justice through public reasoning". In this conceptualization, thus test institutions should be just, by yielding societal benefits and by advancing certain values, but they should also advance justice through public reasoning. It is unclear, however, what Kunnan means by public reasoning, and how it would be implemented in assessment practice. Furthermore, Kunnan's focus on the importance of a test to be beneficial to society betrays a somewhat utilitarian perspective in an approach that is indebted to Rawls and Sen, who prioritize certain 
inalienable individual human over the common good. It is unclear how Kunnan deals with this apparent conceptual mismatch.

Consequently, even though Kunnan's theory suggests adherence to moral and political philosophy, there are a number of inconsistencies between his theory and its original sources. For example, Kunnan has adopted three essential ideas from Sen (2010): the importance of public reasoning (see above), universality, and impartiality. It is unclear, however, how universality would be achieved by "promoting nonparochial, global norms of justice" (Kunnan 2018, p. 93), and perhaps most importantly, it is unclear how Kunnan's approach would lead to impartiality. Kunnan states that "an outside voice [would] provide an impartial perspective" (Kunnan 2018, p. 93), but this deviates crucially from a fundamental point in Sen's (2010) theory of justice. Sen, in line with Nagel (1989), argues that one person can never be objective, since objective illusion (Sen, 201: 161) prevents any one person from seeing the world from any other perspective than their own. Consequently, Sen proposes to include the voices of many different stakeholders with many different objective illusions to comment on the justice of a policy

Kunnan also promotes developing norms of justice in language assessment. Sen, however, argued that a normative approach to justice in untenable because there will never be universal agreement on what perfect justice entails. For Sen, it will be much easier to get people to agree on what is unjust. Building on this idea, Deygers proposes operationalizing justice as minimizing injustice, much in the same way as fairness research focuses on minimizing bias. In Deygers' definition, "a testing policy is unjust if it wilfully and avoidably restricts test takers' freedom without an empirically sound or reasonable motivation"(Deygers 2017; Deygers et al. 2017). A reasonable motivation should rely on empirical data, and could follow Toulmin's argument structure (Toulmin 2003) as it has been proposed in operationalizations of validity (Kane 2013) and fairness (Kunnan 2010).

Deygers (2017) also proposes principles of justice in language assessment which rely on moral and political philosophy. These principles include the need for high-stakes assessment policies to rely on careful and reasonable interpretation of empirical evidence; the need to consult all primary stakeholders about the justice of a testing policy, and to give the people most impacted by that policy the opportunity to reject it on reasonable grounds; the need for testing institutions and individual language testers to be held accountable when they engage in morally reprehensible practices; and the need to respect the privacy of test takers, especially when it concerns biometric data.

In relation to this, Stein (2016) has formulated the rights of test takers, starting from the premise that tests structure access to a primary good (education) and that access to such goods should be fair and unbiased. Stein identifies the right to benefit from measurement, the right to relevant measurement, and the right to objective measurement.

The first right entails that it is unjust to use assessments to the disadvantage of certain groups. As such, it is important to ask the stakeholders of a testing policy whether they can reasonably reject it and its proposed outcomes (see Sen 2010). Secondly, test takers have the right to construct-relevant assessment, and thirdly, they are entitled to assessment practices that are free from bias. Since fairness is a precondition for justice (e.g., Rawls 1971, 2001, Sen 1980, 2010; Young 1990; Nussbaum 2002), the right to objective assessment is primordial. Inevitably, this brings us to the fairness debate in the language assessment literature. 


\section{Justice or fairness? Seeing the forest for the trees}

With so many different conceptualizations of justice and fairness, and an abundance of shifting nuances it is challenging to see whether there is any common ground in the language assessment literature. It is clear that there is agreement on fairness. At a minimum, fairness concerns the absence of bias. There is also general agreement that justice has a broader, value-laden scope that includes an attention for the impact of a test on society. Additionally, different authors agree that justice demands respect for the human rights of test takers (Sen 2010; Nussbaum 2011; Adams 2014; Stein 2016; Deygers 2017; Kunnan 2018), that a just policy must be based on the reasoned use of evidence (Sen 2010; Deygers, 2017; Dworkin 2013; Kunnan 2018), that justice requires acknowledging test takers as equal stakeholders (Walker and Unterhalter 2007; Stein 2016; Deygers 2017), and that fairness is a prerequisite for justice (Rawls 1971; Walker and Unterhalter 2007; Sen 2010; Stein 2016; Deygers 2018; Kunnan 2018).

\section{Justice and power}

In high-stakes language testing there is a coercive power dynamic at play: The person asked to prove a certain ability level will be judged by another, who controls the situation, the judgment, and ultimately the future of the candidate (e.g., Shohamy 2001; McNamara 2012; Spolsky 2013). Authors who have written in the tradition of critical language assessment have typically relied more on Foucauldian poststructuralism (e.g., Foucault 1977) and critical sociology (e.g., Bourdieu 1991) than on Rawlsian philosophy but their purposes have been comparable to the ones propagated in the social justice literature.

Foucault famously criticized examinations for their ceremonial subjection and objectification of individuals:

"In [the examination] are combined the ceremony of power and the form of the experiment, the deployment of force and the establishment of truth. At the heart of the procedures of discipline, it manifests the subjection of those who are perceived as objects and the objectification of those who are subjected"

(Foucault 1977, p. 184-185).

Complementary to these ideas, are Bourdieu's concept of habitus - the unwritten rules and idiosyncrasies that establish group cohesion - and his thoughts on how socially powerful groups use their symbolic capital to implicitly and explicitly superimpose their habitus on society and to exclude thos who do not conform (Bourdieu 1984). Consequently, the knowledge of power asymmetries in language policy were not new when Elana Shohamy published her essential book, The power of tests (2001). But she did translate these principles to a context of language testing, and introduced them to a wide audience. Shohamy was, and is, fundamentally concerned with the impact of tests on people's lives, and with the language ideologies that enable a political agenda in which test play an important part. If these conceptions appear self-evident now, it is largely due to Shohamy's work, and her focus on the impact of tests on individuals, and on the societal role they play.

More recent work in this tradition has focused on the symbolic power on display in language testing procedures (Khan and McNamara 2017), have examined 
the ideological forces behind language policies (Shohamy 2006), or have explored issues of human rights in connection with language ideology (McNamara and Shohamy 2008). A frequent focus of research papers in this domain is language testing in the context of citizenship or permanent residency requirements. Often, these papers discuss policy measures (Shohamy 2009; McNamara 2009; Van Avermaet and Pulinx 2013), or the impact of power issues on individuals involved in citizenship procedures (Khan and Blackledge 2015).

In spite of some differences, however, the Foucauldian and the Rawlsian tradition in language assessment may be quite similar at heart. The two approaches share comparable or compatible goals, conceptions and theories. Bourdieu, for example, is an essential influence on Young, a social justice philosopher. And for some, the distinction between these two traditions even seems somewhat irrelevant. Fulcher (2015), for example, in his philosophical examination of language assessment, mentions Rawls in relation to justice, but ultimately connects justice to Foucauldian matters of power.

\section{JUSTICE, FAIRNESS, AND VALIDITY}

An overview of how justice and fairness have been defined and operationalized in the language assessment literature is incomplete without a discussion of how both relate to validity. The idea that there is a relationship between fairness and validity is well established, but the exact nature of that relationship has been a matter of some debate. In this section we will first discuss how justice and fairness may relate to validity, and then consider briefly how fairness could be operationalized to benefit valid score use.

As was discussed in the historical overview of bias research, the idea that fairness is an essential component of validity has been an essential part of mainstream validity theory (Kane 2010, 2013). Lack of fairness was considered a threat to validity from the early days of language assessment (e.g., Cattell 1905, p. 367). More recently, Messick (1989) saw fairness and justice as components of a unified concept of validity. In Messick's theory, fairness was concerned with test-internal matters, while what we would now call justice (McNamara and Ryan 2011) was test-external, and concerned with the values represented in a test and with the impact of scores on people's lives. This is also largely the position of McNamara and Ryan, who argue that both fairness and justice are validity issues at heart: "most authors following Messick have also increasingly accepted that questions of social values and policy are relevant to understanding the meaning of test scores, and hence their validity" (McNamara and Ryan 2011, p. 163). Davies, too, considered both fairness and justice to be manifestations of validity. In a 2010 contribution he equates justice with validity, and fairness with the absence of construct-underrepresentation, and construct-irrelevant variance. Because both fairness and justice are closely related to validity, Davies argued, there is little merit in attempts at delineating either.

Kane (2010) observes that the relationship between validity and fairness depends on how they are defined. A narrow definition of validity (e.g., limited to construct validity) and a broad definition of fairness (e.g., everything, from avoiding construct irrelevant variance to objective measurement and equal access) would mean that fairness subsumes validity. Conversely, a narrow definition of fairness (e.g., limited to eliminating biased items) and a broad definition of validity (e.g., everything 
having to do with proving any important claim, from construct representation to score use) would mean that fairness is part of validity. Since Kane defines both fairness (equitable treatment and reasonable consequences - see above) and validity broadly, he chooses not to consider either one as subordinate to the other. Rather, he argues that fairness and validity are two ways of answering the same basic question: "Are the proposed interpretations and uses of the test scores appropriate for a population over some range of contexts?" (Kane 2010, p. 177). In later work too, Kane avoids a clear differentiation between fairness and validity, arguing that procedural and substantive fairness are integral components of test development and test validation. Kane's view is compatible with Xi's (2010), who considers fairness and validity to be part of the same framework. Xi sees fairness as comparable validity for all subgroups involved in the testing process. Another variation on this perspective is seen in the Standards for Educational and Psychological Testing (AERA 2014), which states that fairness (defined as equitable treatment of test takers and the absence of bias) vitally contributes to the validity of a test.

Thus, there is general consensus that validity and fairness are interlinked, and most researchers and theoreticians agree that fairness is either a component of validity, or largely coincides with it. A few authors have taken opposing views to the relationship between fairness and validity. Kunnan (2000), for example, proposed a framework in which fairness encompassed both validity and justice - an idea that runs counter to notions proposed by Messick (fairness as part of validity) and Rawls (fairness as a precondition for justice). In more recent work, Kunnan (2018) has elaborated that idea, by considering fairness as a superordinate category that contains both "meaningfulness" (i.e., validity) and lack of bias (for a discussion on meaningfulness and validity, see Weideman 2017).

Since justice is not quite the established research topic in language testing that fairness is, it is unsurprising that the literature on the relationship between justice and validity is not quite as well developed. Messick (1989) and McNamara and Ryan define justice in terms of the effects and consequences of a test, and in terms of the societal values it represents (McNamara and Ryan 2011, p. 165). Thus, logically, they consider justice as a component of validity. Kane does not explicitly develop an argument related to justice, but his discussion of procedural fairness shows that he would be inclined to consider justice as part of validity.

Within the social justice literature, however, validity is commonly considered as an essential component of justice (Stein 2016). A test which is not valid could never be part of a system that is based on "fair equality of opportunity" (Rawls 2001, p. 42) for all. Similarly, for Sen (2010), an instrument which has the power to exclude would need to be based on irrefutable reasoning before the policy could be considered just. This idea has received some uptake in the language assessment literature. For Kunnan (2018) a test cannot be just if test users are not aware of the validity evidence. In a similar vein, Deygers (2017) argues that a test policy can never be just if it does not rely on adequate empirical evidence for its most important claims. Lastly, there are theorists who propose to consider validity a characteristic of a test proper, and contest the idea that the use of a test in a social context is part of validity (e.g., Borsboom and Markus 2013). For better or for worse however, these ideas are not generally acknowledged in the language assessment literature (McNamara and Ryan 2011).

Regarding justice and validity it appears that the general assessment literature sees justice as part of validity, and that the social justice literature considers it the 
other way around. On closer consideration, this apparent conceptual schism may not be quite as wide as it would seem at first sight, since Kane's point about broad and narrow definitions applies here too. A rather narrow definition of justice (i.e., limited to the social consequences of score use), as is typically applied in the language assessment literature would mean that justice is part of validity, while a wide definition would lead to the opposite conclusion. Additionally, justice in the language assessment literature usually focuses on the impact of a test on society, in which case it is reasonable to consider justice as part of test validity (e.g., Messick 1989; McNamara and Ryan 2011). In the social justice literature, however, the scope is wider (e.g., Stein 2016). These authors consider societal institutions, institutional policies, social norms, and structural inequality as the domain of justice. As such, it is reasonable for these authors to consider valid tests as a vital component of a wider educational system.

The above discussion is conceptually important, but largely belongs within the real of theory. In practice, language test developers face more concrete and elemental challenges. Related to fairness, these challenges include but are not limited to avoiding bias, maintaining a consistent difficulty level between test versions, ensuring rater reliability and consistency. It can be quite daunting, even for seasoned test developers, to select the appropriate methodological tools and avoid the many pitfalls. For that reason - even though a full hands-on discussion of the various ways in which fair testing could be promoted to benefit valid score use goes beyond the scope of this chapter - this paragraph identifies a number of methodological approaches to fairness and justice, without aspiring to exhaustiveness.

Weideman (2017) outlines three essential requirements for sound test development: tests must be based on a sound linguistic theory (for an early discussion, see Cronbach and Meehl 1955), they must be in accordance with existing and commonly accepted codes of ethics (though this cannot be enforced, see Davies 2012; Spolsky 2013), and they must qualify as "responsible design" (see also guidelines for good practice e.g., EALTA 2000; ALTE 2001; ILTA 2007). An important aspect of responsible design, is procedural fairness, in the sense that "all test takers [should] be treated in essentially the same way, that they take the same test or equivalent tests, under the same conditions or equivalent conditions, and that their performances be evaluated using the same (or essentially the same) rules and procedures" (Kane 2010, p. 178).

Drawing on Kane, Xi (2010a) has proposed a set of inferences that need to be validated with regards to fairness. Table 1 summarizes the implications of these inferences and the underlying assumptions (see Kane et al. 2017). The table also provides one relevant publication per assumption, and briefly indicates the methodology used in that publication, when applicable.

[insert Table 1 about here]

Most publications on the topic of justice in language assessment have been conceptual (McNamara 2009; Deygers 2017; Khan and McNamara 2017) rather than empirical, and only a few research papers have appeared (see Table 1). These empirical studies have often taken a qualitative approach (e.g., Khan and Blackledge 2015), although a mixed-methods procedure focusing on the impact of false negatives has also been proposed (e.g., Deygers et al. 2017). 
Regardless of the approach taken, an essential prerequisite to fairness and justice, is transparency (Fulcher 2010). It is essential for language testers and score users alike to report fully and openly which studies have been conducted, and what the outcomes were. Without transparency there can be no public debate (Kunnan 2018), which would leave test candidates and score users with insufficient information to adequately select the most appropriate test.

\section{CONCLUSION}

To conclude this chapter, we will briefly consider how fair and just assessment can be enforced. The answer to that is brief: it cannot. There are no binding ethical regulations for language testers, as there are for doctors and lawyers. Language testing organizations have drawn up codes of practice (EALTA 2000; ALTE 2001; ILTA 2007) and minimum standards of quality (ALTE 2007), but these are mostly focused on the more technical and operational sides of language assessment and language test development (Spolsky 2013). They help promote fairness, but not necessarily justice. Freedom from bias, for example, is a widely recognized an aspect of test quality (EALTA 2000; ILTA 2007), and it is even a requirement for becoming a full member of certain professional language testing organizations, such as ALTE (Spolsky 2013).

ILTA's Code of Ethics is focused on justice and human rights, however. Violating it could lead to certain organizations or individuals losing their membership. But, since language testers do not have to be part of a professional organization to develop and administer tests, there are no ways to enforce the moral guidelines encompassed in codes of ethics and codes of practice. Test developers who would wish to disregard ethical standards could not be stopped from doing so, as long as they are not involved in illegal activities (Spolsky 2013).

In spite of this, the pressure from within the language testing community to engage in fair and just assessment, is substantial. Justice, social responsibility and social engagement are the focus of special issues, books, and conferences, and a substantial number of language testers are actively engaged in changing language assessment and language teaching policies across the globe (e.g., Lo Bianco 2014). Moreover, as the field of language assessment has been embracing its social responsibility, the subdiscipline of language assessment literacy (e.g., Inbar-Lourie 2013; Malone 2013) has been researching ways of engaging with educators, policy makers and the wider society to promote fair and just assessment. 


\section{REFERENCES}

Abedi J (2014) Accommodations in the assessment of english language learners. In: Kunnan AJ (ed) The companion to language assessment. John Wiley \& Sons, Inc., Chichester, West Sussex, U.K. ; Malden, MA, pp 1115-1130

Adams M (2014) Social justice and education. In: Reisch M (ed) The Routledge International Handbook of Social Justice. Routledge, London \& New York, pp 249-268

Alderson JC, Urquhart AH (1985) The effect of students' academic discipline on their performance on ESP reading tests. Lang Test 2:192-204. doi: $10.1177 / 026553228500200207$

Allalouf A, Abramzon A (2008) Constructing Better Second Language Assessments Based on Differential Item Functioning Analysis. Lang Assess Q 5:120-141. doi: 10.1080/15434300801934710

ALTE (2001) Principles of good practice for ALTE examinations

ALTE (2007) Minimum standards for establishing quality profiles in ALTE examinations

American Educational Research Association, American Psychological Association, \& National Council on Measurement, in Education (2014) The standards for educational and psychological testing. American Psychological Association, Washington, DC

Aryadoust V (2018) Using recursive partitioning Rasch trees to investigate differential item functioning in second language reading tests. Stud Educ Eval 56:197-204. doi: 10.1016/j.stueduc.2018.01.003

Aryadoust V, Goh CCM, Kim LI (2011) An investigation of differential item functioning in the MELAB listening test. Lang Assess Q 8:361-385

Baker BA, Tsushima R, Wang S (2014) Investigating language assessment literacy: Collaboration between assessment specialists and Canadian university admissions officers. Lang Learn High Educ Berl 4:137-157. doi: http://dx.doi.org.kuleuven.ezproxy.kuleuven.be/10.1515/cercles-2014-0009

Ball SJ (2003) The more things change: Educational research, social class and "interlocking" inequalities. Institute of education, London

Barkaoui K (2014) Multifaceted Rasch Analysis for Test Evaluation. In: The Companion to Language Assessment. John Wiley \& Sons, Inc.

Barkaoui K (2010) Explaining ESL essay holistic scores: A multilevel modeling approach. Lang Test 27:515-535. doi: 10.1177/0265532210368717

Binet A, Simon T (1916) The development of intelligence in children. Williams \& Wilkins, Baltimore 
Blake PR, McAuliffe K, Corbit J, et al (2015) The ontogeny of fairness in seven societies. Nature 528:nature15703. doi: 10.1038/nature15703

Borsboom D, Markus KA (2013) Truth and Evidence in Validity Theory. J Educ Meas 50:110-114. doi: 10.1111/jedm.12006

Bourdieu P (1991) Language and Symbolic Power, 7th ed. edition. Harvard University Press, Cambridge, Mass

Bourdieu P (1984) Distinction: a social critique of the judgment of taste. Harvard University Press, Cambridge, Mass

Boyd K, Davies A (2002) Doctors' orders for language testers: the origin and purpose of ethical codes. Lang Test 19:296-322. doi:

$10.1191 / 02655322021 \mathrm{t} 231$ oa

Boylan M (2004) A Just Society. Rowman \& Littlefield Publishers, Lanham

Carlsen CH (2017) Giving LESLLA-learners a fair chance in testing. In: Proceedings of the 12th LESLLA Symposium. University of Granada, Granada

Cattell JM (1905) Examinations, Grades and Credits. Pop Sci Mon 66:367-378

Chen Z, Henning G (1985) Linguistic and cultural bias in language proficiency tests. Lang Test 2:155-163. doi: 10.1177/026553228500200204

Cleary TA (1968) Test Bias: Prediction of Grades of Negro and White Students in Integrated Colleges. J Educ Meas 5:115-124

Cronbach LJ (1976) Equity in Selection: Where Psychometrics and Political Philosophy Meet. J Educ Meas 13:31-42

Cronbach LJ (1984) Essentials of Psychological Testing, 4th edn. Harper and Row, New York

Cronbach LJ, Meehl PE (1955) Construct validity in psychological tests. Psychol Bull 52:281-302

Darlington RB (1971) Another Look at “Cultural Fairness.” J Educ Meas 8:71-82

Davidson F (2012) Test specifications and criterion referenced assessment. In: Fulcher G, Davidson F (eds) The Routledge Handbook of Language Testing. Routledge, London and New York, pp 197-208

Davies A (2010) Test fairness: a response. Lang Test 27:171-176. doi: $10.1177 / 0265532209349466$

Davies A (1977) The Edinburgh Course in Applied Linguistics, Vol. 4. Oxford University Press, London 
Davies A (2012) Ethical codes and unexpected consequences. In: Fulcher G, Davidson F (eds) The Routledge Handbook of Language Testing. Routledge, London and New York, pp 455-468

De Jong JHAL (1983) Focusing in on a latent trait: An attempt at construct validation using the Rasch model. In: Van Weeren J (ed) Practice and problems in language testing 5. Papers presented at the International Language Testing Symposium. CITO, Arnhem

Dexter EG (1903) High-Grade Men: in College and Out By Edwin Grant Dexter. Pop Sci Mon 62:429-435

Deygers B (2017) Just testing. Applying theories of justice to high-stakes language tests. ITL - Int J Appl Linguist 168:143-162

Deygers B, Van den Branden K, Van Gorp K (2017) University entrance language tests: A matter of justice. Lang Test. doi: 10.1177/0265532217706196

Deygers B, Van Gorp K (2015) Determining the scoring validity of a co-constructed CEFR-based rating scale. Lang Test 32:521-541. doi: $10.1177 / 0265532215575626$

Diederich PB, French JW, Carlton ST (1961) Factors in judgments of writing ability. In: ETS Research Bulletin Series. Educational Testing Service, Princeton, NJ

Dworkin R (2013) Justice for Hedgehogs, Reprint edition. Belknap Press

Dworkin R (2000) Affirmative Action: Is It Fair? J Blacks High Educ 79-88. doi: $10.2307 / 2678715$

Dworkin R (2002) Sovereign Virtue: The Theory and Practice of Equality, Trade Paperback Edition edition. Harvard University Press, Cambridge, Mass.; London

Dworkin R (2003) Equality, Luck and Hierarchy. Philos Public Aff 31:190-198. doi: 10.1111/j.1088-4963.2003.00190.x

EALTA (2000) EALTA Guidelines for good practice in language testing and assessment

Eckes T (2005) Examining Rater Effects in TestDaF Writing and Speaking Performance Assessments: A Many-Facet Rasch Analysis. Lang Assess Q 2:197-221. doi: 10.1207/s15434311laq0203_2

Edgeworth FY (1888) The Statistics of Examinations. J R Stat Soc 51:599-635

Elder C (1997) What does test bias have to do with fairness? Lang Test 14:261-277. doi: $10.1177 / 026553229701400304$

Elder C, Knoch U, Barkhuizen G, Randow J von (2005) Individual Feedback to Enhance Rater Training: Does It Work? Lang Assess Q 2:175-196. doi: 10.1207/s15434311laq0203_1 
ETS (2010) Linking TOEFL iBT TM Scores to IELTS® Scores - A Research Report

Flaugher DL (1974) The New Definitions of Test Fairness in Selection:

Developments and Implications. Educ Res 3:13-16. doi:

10.3102/0013189X003009013

Foucault M (1977) Discipline and punish. The birth of the prison. Penguin, London

Frost K, Elder C, Wigglesworth G (2012) Investigating the validity of an integrated listening-speaking task: A discourse-based analysis of test takers' oral performances. Lang Test 29:345-369. doi: 10.1177/0265532211424479

Fulcher G (2015) Re-examining Language Testing: A Philosophical and Social Inquiry. Routledge, London; New York

Fulcher G (2010) Practical language testing. Hodder Education, London

Fulcher G, Davidson F, Kemp J (2011) Effective rating scale development for speaking tests: Performance decision trees. Lang Test 28:5-29. doi: $10.1177 / 0265532209359514$

Galaczi ED, ffrench A, Hubbard C, Green A (2011) Developing assessment scales for large-scale speaking tests: a multiple-method approach. Assess Educ Princ Policy Pract 18:217-237. doi: 10.1080/0969594X.2011.574605

Giddens A (1979) Central problems in social theory: action, structure, and contradiction in social analysis. University of California Press, Berkeley

Hale GA (1988) Student major field and text content: interactive effects on reading comprehension in the Test of English as a Foreign Language. Lang Test 5:4961. doi: $10.1177 / 026553228800500104$

Harsch C, Martin G (2013) Comparing holistic and analytic scoring methods: issues of validity and reliability. Assess Educ Princ Policy Pract 20:281-307. doi: 10.1080/0969594X.2012.742422

Harsch C, Martin G (2012) Adapting CEF-descriptors for rating purposes: Validation by a combined rater training and scale revision approach. Assess Writ 17:228250. doi: 10.1016/j.asw.2012.06.003

Hume D (1978) A Treatise of Human Nature. Clarendon Press, Oxford

ILTA (2000) Code of ethics

ILTA (2007) Guidelines for practice

Inbar-Lourie O (2013) Guest Editorial to the special issue on language assessment literacy. Lang Test 30:301-307. doi: 10.1177/0265532213480126

Isaacs T, Thomson RI (2013) Rater Experience, Rating Scale Length, and Judgments of L2 Pronunciation: Revisiting Research Conventions. Lang Assess Q 10:135-159. doi: 10.1080/15434303.2013.769545 
Kane MT (2010) Validity and fairness. Lang Test 27:177-182. doi:

$10.1177 / 0265532209349467$

Kane MT (2013) Validating the Interpretations and Uses of Test Scores. J Educ Meas 50:1-73. doi: $10.1111 /$ jedm. 12000

Kane MT, Kane J, Clauser BE (2017) A validation framework for credentialing tests. In: Buckendahl CW, Davis-Becker S (eds) Testing in the Professions : Credentialing Polices and Practice. Routledge, pp 20-41

Kant I (1785) Fundamental Principles of the Metaphysic of Morals. CreateSpace Independent Publishing Platform. (Original work published 1785)

Kaufmann P, Kuch H, Neuhaeuser C, Webster E (2010) Humiliation, Degradation, Dehumanization: Human Dignity Violated. Springer Science \& Business Media

Khan K, Blackledge A (2015) “They look into our lips.” J Lang Polit 14:382-405. doi: $10.1075 / \mathrm{jlp} .14 .3 .04 \mathrm{kha}$

Khan K, McNamara T (2017) Citizenship, immigration laws, and language. In: Canagarajah S (ed) The Routledge Handbook of Migration and Language. Routledge, London \& New York, pp 451-467

Kunnan AJ (2000) Fairness and justice for all. In: Kunnan AJ (ed) Fairness and Validation in Language Assessment. Cambridge University Press, Cambridge, pp 1-13

Kunnan AJ (2018) Evaluating language assessments. Routledge, New York \& London

Kunnan AJ (2014) Fairness and Justice in Language Assessment. In: The Companion to Language Assessment. John Wiley \& Sons, Inc., New York, pp 1-17

Kunnan AJ (2004) Test fairness. In: Milanovic M, Weir C (eds) European language testing in a global context. Cambridge University Press, Cambridge, pp 27-48

Kunnan AJ (2010) Test fairness and Toulmin's argument structure. Lang Test 27:183-189. doi: 10.1177/0265532209349468

Laborde C (2002) The Reception of John Rawls in Europe. Eur J Polit Theory 1:133146. doi: $10.1177 / 1474885102001002002$

Latham $\mathrm{H}$ (1877) On the action of examinations considered as a means of selection. Deighton, Bell \& Co, Cambridge

Li H, Suen HK (2013) Detecting native language group differences at the subskills level of reading: A differential skill functioning approach. Lang Test 30:273298. doi: $10.1177 / 0265532212459031$

Linacre JM (1989) Many faceted Rasch measurement. Unpublished doctoral dissertation. University of Chicago, Chicago 
Linn RL, Drasgow F (1987) Implications of the Golden Rule Settlement for Test Construction. Educ Meas Issues Pract 6:13-17. doi: 10.1111/j.17453992.1987.tb00405.x

Lo Bianco J (2014) Dialogue between ELF and the field of language policy and planning. J Engl Lingua Franca 3:197-213

Lumley T (2002) Assessment criteria in a large-scale writing test: what do they really mean to the raters? Lang Test 19:246-276

Malone ME (2013) The essentials of assessment literacy: Contrasts between testers and users. Lang Test 30:329-344. doi: 10.1177/0265532213480129

Matlock KL, Turner R (2016) Unidimensional IRT Item Parameter Estimates Across Equivalent Test Forms With Confounding Specifications Within Dimensions. Educ Psychol Meas 76:258-279. doi: 10.1177/0013164415589756

McNamara T (2009) Australia: The Dictation Test Redux? Lang Assess Q 6:106-111. doi: $10.1080 / 15434300802606663$

McNamara T (2012) Language Assessments as Shibboleths: A Poststructuralist Perspective. Appl Linguist 33:564-581. doi: 10.1093/applin/ams052

McNamara T, Knoch U (2012) The Rasch wars: The emergence of Rasch measurement in language testing. Lang Test 29:555-577. doi: $10.1177 / 0265532211430367$

McNamara T, Roever C (2006) Language Testing: The Social Dimension. John Wiley $\&$ Sons

McNamara T, Ryan K (2011) Fairness Versus Justice in Language Testing: The Place of English Literacy in the Australian Citizenship Test. Lang Assess Q 8:161178. doi: 10.1080/15434303.2011.565438

McNamara T, Shohamy E (2008) Language tests and human rights. Int J Appl Linguist 18:89-95. doi: 10.1111/j.1473-4192.2008.00191.x

Messick S (1989) Validity. In: Educational Measurement, 3rd edn. American Council on Education / Macmillan, Washington, D.C., pp 13-103

Mill JS (2015) On Liberty, Utilitarianism and Other Essays. Oxford University Press. (Original work published 1861), Oxford

Nagel T (1989) The View From Nowhere, Revised ed. edition. Oxford University Press, New York

Nozick R (1974) Anarchy, State, and Utopia, 2nd edition. edition. Basic Books, New York

Nussbaum M (2002) Capabilities and Social Justice. Int Stud Rev 4:123-135. doi: $10.1111 / 1521-9488.00258$ 
Nussbaum M (2000) Women and human development: The capabilities approach. Cambridge University Press, Cambridge

Nussbaum M (2011) Creating Capabilities. The Human Development Approach. Belknap Press, Cambridge, Mass.; London

Oliveri ME, Ercikan K, Zumbo B (2013) Analysis of Sources of Latent Class Differential Item Functioning in International Assessments. Int J Test 13:272_ 293. doi: $10.1080 / 15305058.2012 .738266$

O'Loughlin K (2013) Developing the assessment literacy of university proficiency test users. Lang Test 30:363-380. doi: 10.1177/0265532213480336

Petersen NS, Novick MR (1976) An Evaluation of Some Models for Culture-Fair Selection. J Educ Meas 13:3-29

Phillips DC (2007) Adding Complexity: Philosophical Perspectives on the Relationship Between Evidence and Policy. Yearb Natl Soc Study Educ 106:376-402. doi: 10.1111/j.1744-7984.2007.00110.x

Pogge T (2010) A critique of the capability approach. In: Brighouse H, Robeyns I (eds) Measuring Justice: Primary Goods and Capabilities. Cambridge University Press, Cambridge, pp 17-61

Rawls J (1971) A Theory of Justice. Harvard University Press

Rawls J (1958) Justice as Fairness. Philos Rev 67:164-194

Rawls J (2001) Justice as Fairness: A Restatement, 2nd edition. Belknap Press, Cambridge, Mass

Reisch M (2014) Social justice and liberalism. In: Reisch M (ed) The Routledge International Handbook of Social Justice. Routledge, London \& New York, pp $132-147$

Rescher N (2002) Fairness. Theory \& practice of distributive justice. Transcaction publishers, New Brunswick \& London

Roemer J (1996) Theories of Distributive Justice. Harvard University Press, Cambridge, Mass

Saida C, Hattori T (2008) Post-hoc IRT equating of previously administered English tests for comparison of test scores. Lang Test 25:187-210. doi: $10.1177 / 0265532207086781$

Sandel MJ (2010) Justice: What's the Right Thing to Do?, Reprint edition. Farrar, Straus and Giroux, New York

Saville N (2012) Quality management in test production and administration. In: Fulcher G, Davidson F (eds) The Routledge Handbook of Language Testing. Routledge, London and New York, pp 395-413 
Sen A (1980) Equality of what? In: McMurrin (ed) The Tanner lectures on human values. University of Utah Press and Cambridge University Press, Salt Lake City, pp 196-220

Sen A (1992) Inequality re-examined. Oxford University Press, Oxford

Sen A (1993) Capability and well being. In: Nussbaum M, Sen A (eds) The quality of life: Studies in development economics. Oxford University Press, Oxford, pp $31-66$

Sen A (2010) The Idea of Justice, 1st Edition edition. Penguin, London

Shaw S, Imam H (2013) Assessment of International Students Through the Medium of English: Ensuring Validity and Fairness in Content-Based Examinations. Lang Assess Q 10:452-475. doi: 10.1080/15434303.2013.866117

Shohamy E (2006) Language Policy: Hidden agendas and new approaches. Routledge, London \& New York

Shohamy E (2001) The Power of Tests. Pearson, New York

Shohamy E (2009) Language tests for immigrants: Why language? Why tests? Why citizenship? In: Hogan-Brun G, Mar-Molinero C, Stevenson P (eds) Discourses on language and integration. John Benjamins Publishing, Amsterdam, pp 45-60

Spolsky B (2013) The Influence of Ethics in Language Assessment. In: The Companion to Language Assessment. John Wiley \& Sons, Inc.

Spolsky B (1997) The ethics of gatekeeping tests: what have we learned in a hundred years? Lang Test 14:242-247. doi: 10.1177/026553229701400302

Spolsky B (1981) Some ethical questions about language testing. In: Klein-Braley C, Stevenson DK (eds) Practice and problems in language testing. Peter Lang, Frankfurt am Main, Germany, pp 5-30

Spolsky B (1995) Measured Words: The Development of Objetive Language Testing. Oxford University Press (Sd)

Stein Z (2016) Social Justice and Educational Measurement. Routledge, Oxon and New York

Stern W (1914) The psychological methods of testing intelligence. Warwick \& York, Baltimore

Swinton S, Powers D (1980) Factor analysis of the Test of English as a Foreign Language for several groups. Educational Testing Service, Princeton, N.J.

The State of Louisiana (1963a) Louisiana literacy test

The State of Louisiana (1963b) Registration procedure 
Thorndike RL (1971) Concepts of Culture-Fairness. J Educ Meas 8:63-70

Toulmin S (2003) The Uses of Argument. Updated Edition., Updated edition. Cambridge University Press, Cambridge, U.K. ; New York

UN General Assembly (1948) Universal Declaration of Human Rights

Valentini L (2012) Justice in a Globalized World: A Normative Framework, 1 edition. Oxford University Press, Oxford

Van Avermaet P, Pulinx R (2013) Language Testing for Immigration to Europe. In: The Companion to Language Assessment. John Wiley \& Sons, Inc.

Van den Branden K (2015) Sustainable Education: Exploiting Students' Energy for Learning as a Renewable Resource. Sustainability 7:5471-5487. doi: $10.3390 / \mathrm{su} 7055471$

Walker M, Unterhalter E (eds) (2007) Amartya Sen's Capability Approach and Social Justice in Education. Palgrave Macmillan, Basingstoke and New York

Walters SF (2012) Fairness. In: Fulcher G, Davidson F (eds) The Routledge Handbook of Language Testing. Routledge, London and New York, pp 469479

Weideman A (2017) Does responsibility encompass ethicality and accountability in language assessment? Lang Commun 57:5-13. doi: 10.1016/j.langcom.2016.12.004

Weigle SC (2002) Assessing Writing. Cambridge University Press

Weintrob J, Weintrob R (1912) The influence of environment on mental ability as shown by Binet-Simon Tests. J Educ Psychol 3:577-583

Willner LS, Rivera C, Acosta BD (2008) Descriptive study of state assessment policies for accommodating English language learners. George Washington University Center for Equity and Excellence in Education, Arlington, VA.

Wood AW (2008) Kantian ethics. Cambridge University Press, Cambridge

Xi X (2010a) How do we go about investigating test fairness? Lang Test 27:147-170. doi: $10.1177 / 0265532209349465$

Xi X (2010b) Aspects of performance on line graph description tasks: influenced by graph familiarity and different task features. Lang Test 27:73-100. doi: $10.1177 / 0265532209346454$

Young IM (2011) Responsibility for Justice. Oxford University Press, Oxford

Young IM (1990) Justice and the Politics of Difference. Princeton University Press, New Jersey 
Zeidner M (1987) A comparison of ethnic, sex and age bias in the predictive validity of English language aptitude tests: some Israeli data. Lang Test 4:55-71. doi: $10.1177 / 026553228700400106$ 